\title{
Erratum to: Early Ordovician reefs in South China (Chenjiahe section, Hubei Province): deciphering the early evolution of skeletal-dominated reefs
}

\author{
Natsuko Adachi · Jianbo Liu • Yoichi Ezaki
}

Published online: 8 July 2012

(C) Springer-Verlag 2012

\section{Erratum to: Facies}

\section{DOI 10.1007/s10347-012-0308-2}

Unfortunately, the family name of the third author was misspelled in the online published article.

The correct name is Yoichi Ezaki.

The online version of the original article can be found under doi:10.1007/s10347-012-0308-2.

N. Adachi $\cdot$ J. Liu

School of Earth and Space Sciences, Peking University,

Haidian, Beijing 100871, People's Republic of China

Present Address:

N. Adachi $(\square)$

Department of Geosciences, Osaka City University,

Sugimoto, Sumiyoshi-ku, Osaka 558-8585, Japan

e-mail: naadachi@sci.osaka-cu.ac.jp

Y. Ezaki

Department of Geosciences, Osaka City University,

Sugimoto, Sumiyoshi-ku, Osaka 558-8585, Japan 